\title{
Early Childhood Student Teachers' Observation and Experimentation of Creative Practices as a Design Processes
}

\author{
Janaina Minelli de Oliveira ${ }^{1 *}$, Eliana E. Gallardo-Echenique ${ }^{2}$ \\ ${ }^{1}$ Department of Pedagogy, Universitat Rovira i Virgili, Spain \{janaina.oliveira@urv.cat\} \\ 2Department of Pedagogy, Universitat Rovira i Virgili, Spain \{egallardoechenique@gmail.com\} (1) \\ Received on 30 December 2014; revised on 7 January 2015; accepted on 19 February 2015; in press on 15 April 2015; published on \\ 15 July 2015
}

DOI: 10.7821/naer.2015.4.122

\begin{abstract}
In this paper, we address the guidance of student teachers in initial training in schools as an invaluable opportunity to raise creative learning awareness. The objective of this present research is to develop guidance strategies for guiding the identification of creative practices and for analyzing that moment as a "way of knowing". We analyze how to mentor future teachers so they feel willing to promote student engagement and creative thinking through their own practices. We adopted a case study approach guided by multimodal principles. We found that triangulation of individual interviews, focus group discussions and a diary of class observation was a useful strategy in the guidance of student teachers in initial training in schools. Results show these strategies allowed them to become more accepting of unpredicted or undesired results, as they approached their sessions' designs as forms of experimentation. We argue it is essential to guide future educators in the critical analysis of the "standard classroom", helping them design creative alternatives through collaborative experimentation.
\end{abstract}

KEYWORDS: CREATIVE TEACHING, CREATIVE ACTIVITIES, TEACHER EDUCATION. CASE STUDIES

\section{INTRODUCTION}

During initial teacher training programs that take place in schools, future teachers have both in-service teachers and faculty tutors as mentors. During this period, future teachers have the opportunity to engage in creative thought production through practical application by observing and participating in creative learning environments. However, teaching for creativity is a demanding process which cannot be made routine. Standard classroom practices, often characterized by teacher-directed, atomized and reductive worksheets, quizzes, exercises and tests is a solution many teachers turn to when facing everyday classroom dilemmas (Ball, 2002). Johnston \& Hayes (2008) suggest that high level of order achieved at the expense of student engagement may be producing a new axis of disadvantage within schooling, where students are perceived not to have the abilities, cognitive skills or social and emotional maturity to be autonomous learners within an interactive learning paradigm.

The objective of this present research is to develop guidance strategies in the identification of creative practices and in the analysis of that moment as a "way of knowing"? We analyze how to mentor future teachers so they feel willing to promote student engagement and creative thinking through their own practices.

The case study reported here is part of an initial teacher training program which involves an average of 190 students a year. Student teachers spend 285 hours in schools as part of their undergraduate curriculum. Internationally, the European Commission has acknowledged that "schools and initial education play a key role in fostering and developing people's creative and innovative capacities for further learning and their working lives” (Cachia, Ferrari, Ala-Mutka, \& Punie, 2010, p. 9) through the studies developed by the Institute for Prospective Technological Studies. National guidelines for childhood education in Spain define the development of students' ability to regulate their own learning, trust their skills and knowledge and to develop creativity, personal initiative and entrepreneurship as part of the aims of its educational system (Ley Orgánica 2, 2006). Local education laws in Catalunya establish using intuition, improvisation, imagination and creativity in observing and listening as areas of early childhood education (Decret 181, Generalitat de Catalunya, 2008). Teacher education for the promotion of creative learning environments, however, seems to be as obviously necessary as passed by in undergraduate programs. We argue student teachers need specific training, and should be offered structured learning opportunities so they become aware of the importance of knowing and encouraging ways of promoting creativity in their future practice.

In writing this paper we hope to contribute to the acknowledgement of the identification of young people's creative capacities and the production of the particular conditions in which they can be realized as student teachers' learning objectives in undergraduate curriculums. We believe it is essential to enable both children and future teachers to make the most of themselves and take the best advantage of the opportunities and uncertainties that they face in a fast changing world.

\footnotetext{
*To whom correspondence should be addressed:

Faculty of Educational Sciences and Psychology

Universitat Rovira i Virgili, Carretera de Valls s/n,

43007 Tarragona, Spain
} 


\section{THEORETICAL BASIS}

\subsection{Creative Learning}

A review of the literature on creative learning reveals it is an uneasy academic territory where dispute is the norm, rather than the exception. The tension runs in different levels, for it is not always clear how to reconcile the interests, expectations and demands of national educational agencies, on the one hand, and schools on the other; nor those of schools as opposed to those of teachers'; nor those of teachers as opposed to those of students'. Something seems to be wrong in this type of 'opposition' elaboration, since all these actors are actually supposed to collaborate, rather than compete. However apparently contradictory, such an intrinsic dispute is actually due to the very nature of creativity. As we move away from hard core standard practices and approach creative designs, we enter a territory where individual expression does not easily produce adaptation to society and culture. In this space, originality and innovation stand in line of collision with sanctioned norms and repetition, offering alternatives not always welcome in standard practices.

According to the editors of The Routledge International Handbook of Creative Learning, "at its most basic, the idea of creative learning stands in opposition to a steady diet of teacherdirected, atomized and reductive worksheets, quizzes, exercises and tests, many of which render the teacher a mere delivery agent for a syllabus developed elsewhere" (Sefton-Green, Thomson, Jones \& Bresler, 2011, p. 2). Two areas stand out in creative learning: teaching for creativity and teaching creatively. The objective of the first area would be to increase creativity in general. Its interventions, principles and practices are aimed at making children and young people more creative. It is therefore, more overtly focused on the creativity of the learner. Teaching creatively, in turn, draws attention to the structure and organization of schools and classrooms, to the production of teaching materials and to the interactions between teachers and students in order to change curriculum, pedagogy and assessment. This area is in search of exciting, innovative, engaging and often memorable pedagogy.

In few, if any, other fields of inquiry will the researcher be more evidently bound to a broad understanding of what the aims of education are and what type of world construing practices his or her intellectual activity is aligned to. Banaji and Burn (2007) and Banaji (2011) map different rhetorics of creativity, each of them constructing different possible worlds: The creative genius; democratic creativity and cultural (re)production; ubiquitous creativity; creativity for social good; creativity as economic imperative; play and creativity; creativity and cognition, the creative affordances of technology; the creative classroom; and last but not least, the creative arts and political challenge. These different rethorics can be considered to fall into two paradigms in the literature of creative learning, which could be described as a paradigm of competition and a paradigm of collaboration.

In a paradigm of competition, creativity is seen as pivotal in economic production and enterprise. The socio-economic circumstances behind the educational interest in creativity receive special relevance (Shaheen, 2010). In this literature tradition, investment in creativity directly addresses the neoliberal need to restructure capital with basically two clear objectives: "the need for new products for new markets to ensure continuous growth through the turnover of novelties and shifts to a knowledge economy where especially the exploitation of intellectual property is another engine for wealth creation"
(Sefton-Green \& Bresler, 2011, p. 12). In a knowledge society characterized by the ubiquitous presence of immaterial labor, creativity is seen as a resource integral to economic life; it is the raw material of capitalist organization that sustains capital and is exploited by it (Jones, 2011).

Creative stimuli, in a paradigm of competition, promote some freedom from standard practices and are nurtured with the objective of the renewal of the range of goods and services available to the markets. Here, creative thought is welcome as long as it generates the kind of products which reinforce capitalist structures. As Drotner (2011, p. 78) argues, "the harnessing of creativity for knowledge economies is part of a neo-liberal paradigm that takes many forms and inflections". Developed countries participating in a global knowledge economy have become dependent upon the shaping and sharing of intangible forms of production such as information, entertainment, services and knowledge. Educational systems which are able to produce populations endowed with competences that may facilitate innovation within these areas become transnational organizations' strategic lines. A globalized, rapidly developing technological society expects children to learn to take initiatives, to verbalize, and imagine possible futures, to be flexible and behave with self-discipline and to be creative (Singer, 2012).

Fortunately enough, not all the creative potential of the human mind is highjacked by neo-liberalism, the flexible accumulation model of modern capitalism and market demands. An alternative argument offering a rationale for creative and cultural education does exist. This line of literature on creativity, inherent to postEnlightenment thinking, could be described as a paradigm of collaboration. Vygotsky is a strong influence here: creativity is present whenever symbolization occurs; it is part of the human capacity for social semiosis (Vygotsky, 2004). Therefore, all forms of meaning-making practices are creative in nature. Creativity is taken as universal capacity, socially developed, but that does not flourish in all conditions. Constructivist and pragmatist research and educators here aligned tend to believe that creativity is a social phenomenon, highly dependent on the environment. As Darras (2011, p. 90) points out, while creativity "may be caused, nurtured and developed through appropriate practice, technique and strategy, it can also be curbed, inhibited or broken when the environment is not socially or emotionally favourable".

Collaboration paradigm researchers and educators may deliberately choose to approach education matters not from a political point of view, but from a social and cultural one. From this perspective, as Kress (2011) points out, satisfying the requirements of the economy agenda becomes less important than answering the question: what is it that education should offer so that those in school might live productive lives in their near and medium-term individual and social futures? 'Productive' here is not primarily related to goods and services, but to well-being. The demands here are those that place human needs for personal fulfillment and emotional well-being as nonnegotiable values at the basis of educational purposes. There is a strong argument against the 'marketisation' of creative thinking, highlighting the need for wisdom in what creativity is used for, or harnessed in learning (Craft, 2005; Craft, Gardner \& Claxton, 2008). Mayor (1999) makes an appeal for the promotion of art education and creativity in schools to help construct a culture of peace, alerting us on the importance and influence of the creative spirit in shaping human personality that brings out the full potential of children and adolescents. A creative learning 
awareness, we argue, should be ideologically engaged in the creation of wise educational futures, sensible to sustainable and equitable models of human development. It implies the understanding that learning is not only an academic endeavor. It is taken as a social, spiritual and emotional endeavor. As the "All our Futures" report suggests, schools must find ways of enabling young people to explore and express their own emotions and feelings in positive and constructive ways.

Challenging as it is, this approach differs from a notion of educating for reproduction, which is based on the presumable stability of cultural and social forms. As Kress (2011) points out, stability and authority are soulmates. This is why resistance to creative learning will not be seen as an organized educational movement, but is present whenever teachers are ready to sacrifice student engagement to order and control. Much teacher practice is based in the assumption that teachers can simply reproduce social and cultural forms, doing things the way they have always been done, and in the end students will learn. Sullivan (2011) puts it sharply: "Within most educational communities these days, individuals have to make their worlds according to what is expected from them, and the tendency is to be satisfied with sameness. Our educational instincts remain locked into a prescriptive mindset that assumes learning is uniform and predictable.” Teachers make choices all the time which either reinforce or break conventions. The choices they make depend, among other things, on "their 'willingness' (or power) to bear the consequences of resisting convention and the extent to which they have been inducted into social convention" (Jewitt, 2006, p. 22).

It may be difficult to convince teachers to let go of familiar practices and embrace creative learning. In settings where the standard classroom is successful, it is not easy to justify the need for more creative teaching and learning, and in settings where it is not successful, Hayes (2011, p. 200) argues, "it is difficult for teachers to let go of the perception of control afforded by standard classroom practices”. Reproduction, maintenance, conservation and tradition are all signs of standard practices, lacking creativity and educating for the nostalgic aspirations of a stability era. However, as shown by Thurlings, Evers and Vermeulen (2014), various reasons, such as rapid technological and social changes in society, underline the necessity for innovative teacher behaviours.

In the everyday experience of the classroom, emphasizing creativity in education is part of a deliberate effort to draw back from the excesses of a highly regulated, performance-based audit culture. As Hayes (2011, p. 201) points out, "systematic efforts to control teachers, as well as teachers' efforts to control students, can work against creativity”. Where threats to school or teacher authority arise, the most common solution applied is implementation of the model of 'standard classroom', that is, "a teacher-centered classroom in which students sit in rows and the dominant focus next to learning is control” (Ball, 2002, p. 78). The standard classroom, with the seductive sense of control and order it affords, is not easily disrupted in ways that support conditions more conductive to creativity. However, it is imperative to understand teachers' resolving of the tension between creativity and control through the adoption of standard classroom practices as a pedagogical approach that meets the needs of an education for times of stability.

The problem, we must acknowledge, is at the very basis of what we consider to be the aims of education. The foundations of the present education system were designed to meet the needs of a world that was being transformed by industrialization at the end of the nineteenth century (NACCCE, 1999). In other words, actual education systems have been largely shaped by the needs of an industrial economy and by particular and now revised views of ability and intelligence. In an era of stability, practices are fixed and stable, and achievement is judged by competent performance of existing practices. In this context, creativity is rare, exceptional -not to say almost unwelcome. Standard classroom practices therefore pose difficulties to the promotion of creative learning, whetherwe align ourselves with a collaborative ideological perspective or a competitive perspective. The challenges of 21st century education require a renewal of pedagogical strategies.

We are living in different times now. On the cultural, semiotic and technological side, the world of communication has undergone a revolution of the profoundest kind: messages are now ordinarily multimodal, the medium of the book has been replaced by the medium of the screen, which now dominates both production and dissemination (Kress, 2003, 2006, 2011). In this new world, practices are not fixed or stable; achievements are judged in terms of aptness of response to changing purposes, demands and the needs for a specific task. Educating in times of instability implies welcoming creativity back in the learning process as something usual. Students should not be seen as users of norms (reproducing patterns) but as constantly challenging and transforming them. Learning is seen here as a complex process of resemiotization: resources for representation are never simply used, rather they are always transformed in their use. Communication practice, therefore, is always innovating. Transformation by use is the normal condition for meaningmaking.

Learning as representation guides individuals in the development of a full understanding of their social environment and its demands. Learners have interests, which are taken into account by their teachers, and act as agents in a process of design. Design applies to media of production and dissemination, as much as it does to modes of representation. This scenery radically opens new possibilities of action and interaction between teachers and students and among students themselves.

\subsection{Pre-service teacher training for creativity}

Special attention is needed during the early years of education. If we are to promote creative thinking, and no matter which paradigm we are aligned to, we should resist a tendency to spend more and more time filling out phonics worksheets and memorizing math flashcards in the first years of schooling. Resnick (2007) argues that kindergarten is becoming more like "the rest of school", when "exactly the opposite is needed: instead of making kindergarten like the rest of school, we need to make the rest of school (indeed, the rest of life) more like kindergarten.” The author describes thinking creatively as a spiralling process in which children imagine what they want to do, create a project based on their ideas, play with their creations, share their ideas and creations with others, reflect on their experiences - all of which leads them to imagine new ideas and new projects. This is precisely the type of process which becomes progressively rarer as we develop in most formal educational systems. Sadly, creative thinking may be becoming scarce in kindergarten too and researchers have not been paying enough attention to it either. At the present time, Davies, JindalSnape, Digby, Howe, Collier and Hay (2014) present a 
systematic review of 210 educational research, policy and professional literature between 2005-2011 identifying only 17 publications that met the inclusion criteria and contained findings relating to teachers' roles in promoting creativity, and 18 on how teachers can be supported for this. The evidence suggests that teacher skills, attitudes, willingness to act as role model, awareness of learners' need, flexible lesson structure, particular types of classroom interaction are important for teaching for creativity.

It is essential to support future teachers to position themselves as creative designers. As shown by Chan and Yuen (2014), belief in creativity and creative personality are both predictors of teachers' creativity-fostering behaviors. That highlights the importance of guiding future teachers in the development of a full understanding of the affordances and limitations of the standard classroom and its technologies, such as phonic worksheets and memory flash cards. Helping future teachers to position themselves as creative designers also implies offering them opportunities to identify, imagine, create, implement and reflect on strategies to promote creative thinking. That means future teachers should experience creative thinking processes themselves. As Craft (1997, p. 92) points out, "core to being a creative educator and fostering creativity in learners is willingness to reflect critically on practice, and to adapt plans and practice as appropriate”. Notably, Abrami, Bernard, Borokhovski, Waddington, Wade and Persson (2014) highlight the opportunity for dialogue, the exposure of students to authentic or situated problems and examples, and mentoring as positive effects on critical thinking skills. Initial teacher training programs offer an invaluable opportunity to bring theory, practice and criticism together, raising student teachers' awareness of creative learning.

However, it is important to consider mere exposure to experiences does not necessarily translate positively into classroom practice: two student teachers having similar experiences will benefit from them in manifestly different ways (Hayes, 1999). Li (2009) identified student teachers' tendency to meet their classroom teachers mentors' expectations in their teaching practice. Faculty supervising tutors have the responsibility of helping student teachers to incorporate their accumulated insights on creativity into their practical teaching and adjust their existing notions about teaching until they have penetrated creative learning awareness.

\section{STUDY METHOD}

We wanted to explore the guidance of student teachers in initial training in schools as an invaluable opportunity to raise creative learning awareness. As previously stated, the objective of this present research was to develop guidance strategies in the identification of creative practices and in the analysis of that moment as a "way of knowing". Specifically, we analyzed how to mentor future teachers so they feel willing to promote student engagement and creative thinking through their own practices.

We adopted a case study approach (Yin, 1994; Yuen, Law \& Wong, 2003) guided by multimodal principles principles regarding class observations (Jewitt, 2006) and a socio-cognitive perspective for field notes and transcribed data interpretation (Van Dijk, 2009).

\subsection{Sample}

This project drew on 16 student teachers participating in an initial teacher training program in schools from January through
March in 2013. They were all female, their age ranging from 21 to 27 years old. The group included 9 students with no previous teaching experience and 7 students with some experience in informal education like summer camps. None of the participants had considerable experience in formal settings. Pseudonyms are used in reporting the findings. In this present case study, we will mainly focus our analysis on the class observations of one of these participants and draw on general field notes, interviews and group discussions.

\subsubsection{Data gathering}

The data collection methods we used were as follows:

We used three focus group interviews to explore and broaden up students' definitions of and attitudes toward creativity. Each focus group session lasted around an hour and fifteen minutes and consisted in semi-structured discussions. In the first session, the interviewer presented the student teachers with the following statements which had the intention to raise discussion among the participants and incite reflection: "Creative teaching may be seen as associated with lack of discipline in education"; "Creativity is just a matter of letting imagination go"; "Creativity is a talent of few"; "Creativity is only associated only with the arts."; "Creativity cannot be taught."; "Creativity emerges out of freedom of expression and the lack of inhibitions or restrictions"; "Creativity is an entirely individual process"; "Teaching for creativity takes time that could be devoted to literacy and mathematics."; "Creative education can be promoted in all areas of the curriculum." and finally "If the teacher is teaching creatively, he or she is teaching for creativity". Following the same procedure, in the second session the participants were presented with the following statements to prompt self-assessment: "I consider myself a creative person”; "My teaching is creative”; "My teaching practice encourages the creativity of my students"; and finally, "My work environment favors the development of my own creativity". In the third final focus group session, each student teacher presented to the rest of the group the ideas and activities they had planned for the class intervention each of them was supposed to put into practice in their schools. Each presentation was followed by comments on the more creative aspects of the proposal and suggestions for improvement.

Each participant elaborated an observation diary. During one month (twenty working days), students were supposed to describe any creative learning practice they identified in their observation, some of which were discussed in the focus group interviews. The student teachers were prompted to apply the grid present in Johnston and Hayes (2008) in order to analyze teacher control and student engagement in the tasks observed. They were free to include here a variety of data, such as observations, analyses, sketches, quotes, student comments, scores, thoughts, and feelings.

During their training program, student teachers were supposed to elaborate one class intervention and put it into practice. We held individual informal discussions on their teaching plans previous to the intervention as responding to creative learning principles; we observed their class taking notes, and finally we held additional discussions after students' classes to jointly evaluate their job regarding creative 
learning. Each participant had at least one discussion session previous to their teaching and one afterwards.

Finally, we interviewed each participant formally at the end of their training program. Those were semi-structured interviews that lasted around forty-five minutes. Each participant was guided in the revision of how their own thoughts on creativity and creative learning evolved over time. Drawing on field notes, the interviewer reminded the students sentences they themselves had stated during the focus group sessions. The participants were invited to elaborate their own conclusions.

\section{STYLES}

Drawing on field notes and transcript data from class observation, we will briefly report 1 session which is both representative of the session observation corpus and exemplary of the major themes extracted from our case study general findings.

\section{Roses' class}

Rose spent her initial teacher training period in a group of 26 four year olds. In this class, she gave continuation to a learning project which had begun weeks ago. In previous sessions, the teacher and Rose had introduced the students to the observation of the weather. The children had been guided into the observation of how it varies and during the whole month of March, the students had been collecting data on a daily basis. The teacher and Rose hung a thermometer outside the class and a plastic bottle at the window. Every day they would dedicate a moment to talking about what the weather was like, checking the temperature on the thermometer and if there was any water in the plastic bottle - which would have been a sign of rain. They had been putting down the temperature and the type of weather in the class schedule. This time Rose wanted to introduce the students into the graph representation of the data they had collected. She put a big square sheet on the board. In the abscissa axis, she marked the 10 previous days. She asked the students what the temperature had been each day in order to complete the vertical axis. Rose herself completed the graph with the help of the students, who had to check their class calendar. After marking the temperature of each day making a big dot on the graph, she united the points in a line. Rose asked the students what that line on the graph meant and then explained we use graphs to make a visual representation of information, like all the data they had been collecting on the weather: if the line went down, it meant the temperature had fallen; if it went up, the temperature had risen; if it was straight, it meant the temperature had not varied much. Then Rose proposed them to learn another type of graph, a pie. She handed out a sheet of paper with a pie on it. Now the students were supposed to complete the chart themselves. Rose asked the students for suggestions on the colors they wanted to represent each type of weather on the chart legend. As there were more suggestions than types of weather, they voted. It was interesting to see that students turned that moment into a competition. Those students who had voted the chosen colors celebrated as if they had won a game. Then Rose explained thateach part of the pie represented a day of the week. They were supposed to check the class calendar and the chart legend, and finally paint the pie accordingly. There was some confusion, many students asking what they should do and how they should paint the graph. Many did not understand the procedure to complete their pies. Rose helped them count how many days had been sunny the week before, then asked them what colour they should use for sunny weather, and finally told them how many parts of the pie they should paint. It is difficult to tell how many students could have correctly performed the activity because Rose gave them the correct answer before they could make mistakes. A challenging mathematics exercise suddenly became a painting activity. Students had a good time painting the pie. They handed their work in and the teacher put them away in files. The session was over.

Field notes and transcript data from class observations were then analyzed from a socio-cognitive perspective of Critical Discourse Analysis. We drew a list of four semantic macro structures or major themes, which are described in the next session: "Worksheets and quizzes"; "teacher control in class"; "the correct answer"; and finally "where is play?" These macrostructure have been considered to synthesize statements, topics of themes present in the data analyzed. According to Van Dijk (2009), semantic macro structures are what discourses are globally about: "They are mostly intentional and consciously controlled by the speaker; they embody the subjectively most important information of a discourse, express the 'overall' content of mental models of events (...)” (Van Dijk, 2009, p. 68).

\subsection{Major themes}

\subsubsection{Worksheets and quizzes}

Rose spent her teacher training period in a school where she had the opportunity of observing many creative practices and she believed she could use worksheets in a creative way. During our focus group interviews, some student teachers became highly critical of atomized exercises and reported having observed continuous delivery of worksheets and quizzes to the students. Others shared opposite experiences, having been able to observe how their tutors built learning projects out of students' ideas and interests. Based on their observations, the student teachers related the use of worksheets in the classroom with the need to keep the kids sat down, in a controlled environment which met the expectations of both school principals and the parents. However, worksheets, they mentioned, provided the type of evidence which was easily recorded to be shown to families and other colleagues, demonstrating how class time had been invested. Tutors who chose to build learning projects out of students' interests also had evidence of their students' learning, some of which were collective productions, such as a murals, but some were also worksheets used to reinforce some kind of learning or introduce an activity.

In our observation and later discussion with Rose, it became clear she wanted to offer a challenging worksheet to her students, making them think analytically in order to complete the task proposed. However, confusion generated by students who did not understand what they were supposed to do made her feel uncomfortable. Rose felt nervous at the students' simultaneous asking and standing up to check what their classmates had done. She agreed she could have given them more opportunities to figure out 'the correct answer' and realized how important it is to be prepared to deal with one's own emotions when teaching, even in the most ordinary procedures. 


\subsubsection{Teacher control in class}

Rose began to feel uncomfortable when her students expressed their doubts through simultaneous talking, raising hands and standing up. At this moment she felt she was losing control of the class. In the focus group interviews, student teachers manifestly identified teacher control as maintenance of class discipline and order. They initially perceived a reduction of teacher control, necessary in teaching by creative principles, as negative and undesirable. In this initial stage, the participants considered having planned their session thoroughly and being able to keep students attentive and silent as signs of teacher control. In the individual discussion sessions, they began to resignify such perceptions. Teacher control was then established as related to a pedagogic objective. Actually, in our discussion after her class, Rose acknowledged having lost control. She told the students the correct answer to the worksheet so they stopped making such a fuss and she felt the class was in order again. It was interesting to notice the level of self-criticism of this young student teacher in her initial training period. Rose did not consider inadequate her loss of control when the students began talking and standing up. In her own analysis, it was her response to that, which she wished she had been different, what she understood as loss a field for improvement. This is a very important aspect because it points towards a re-interpretation of teacher control as a way of aligning attitudes and feelings with pedagogical objectives, not with external expectations of discipline and order.

\subsubsection{The correct answer}

Students' lack of understanding of how to paint their worksheet pie correctly was definitely a source of discomfort for Rose even if she knew they were only 4 years old. In our discussion just after her session, she said there was a correct answer to the exercise and she felt it was important that all the students got to that point. We discussed about giving them the opportunity of painting the pie as they could and then comparing the results to show what an example of a correct solution would be, but Rose was not satisfied with that. She felt uneasy about keeping the worksheets of students who had not understood how to analyze the graph. It was like keeping proof of failure, what would the parents or the tutor think? There is considerable pressure for getting the correct answer even at such a young age, as we could observe in many occasions in our students' sessions and during our discussions. Some student teachers reported, for example, their tutors would cut or correct their students' drawings because they had been done lousily, meaning the kids had painted out of the borders they were supposed to. In Rose's session having the worksheet painted correctly became more important than making sense of the exercise. Students' mistakes were not seen as a natural part of learning, but as an undesirable evidence of bad teaching. There was little space for error, which would be considered as failure. Even when the teacher is apparently convinced it is possible to use worksheets as part of a creative learning approach, it is not simple, clear or easy how to balance experimentation and evaluation procedures.

\subsubsection{Where is the play?}

Rose's proposal is a very interesting one because she firmly believed it is possible to teach according to creative principles in all areas of the curriculum and this was why she chose to work with mathematical representation of weather observation in her session. However, there was no play in the whole session. It is interesting to note in the focus group sessions, the student teachers, including Rose herself, had repeatedly emphasized the need to provide kids with moments of play. As educators, we have to make the effort to remember they are kids, but they do not need to "remember" they are young and play is simply a part of how they think. As the kids think creatively and play is intrinsically part of that, they will try to change anything adults and teachers present to them into play. This actually happened when Roses' students understood the selection of colors for the pie through voting as a kind of competition. There was celebration for those who had voted the picked colors. In many occasions during our session observations, we heard our student teachers or their tutors say to the students they had some work to do, in order to introduce a new activity. If you think of a bunch of four year olds, play should be a much more frequently heard word than work, but often this is not the case in kindergarten. Again, even when the teacher has apparently decided to apply a creative learning approach, it is not simple, clear or easy how to welcome play and fun into the structure and seriousness of formal education.

\section{CONCLUSIONS}

In this study we found that triangulation of individual interviews, focus group discussions and a diary of class observation was a useful strategy in the guidance of student teachers in initial training in schools. This methodology made possible to raise creative learning awareness among our student teachers, making them more critical of their own emotions and attitudes while teaching. The participants verbalized criticism of decontextualized teacher-directed, atomized and reductive worksheets, quizzes, exercises and tests (Sefton-Green, Thomson, Jones \& Bresler, 2011), expressing willingness to structure learning environments that are more open to creative experimentation. It was interesting to notice how the guidance strategy used in this research also allowed future teachers to become more accepting of unpredicted or undesired results, as they approached their sessions' designs as forms of experimentation. They were fully aware creativity may be conceptualized in many different ways (Banaji \& Burn, 2007; Banaji, 2011) and felt free to explore alternative ways to perform their class interventions because they knew there was not a single correct answer. They were no longer satisfied with sameness (Sullivan, 2011). In this sense, though many student teachers pointed out aspects they would treat differently in the future, none of them felt dissatisfied with the sessions they had taught. That means they learned how to stand back and look at their teacher training period as a "way of knowing", and at the observation or experimentation of creative practices as part of design processes. We firmly recommend mentors of future teachers to explicitly promote the understanding and adoption of creative practices. Individual interviews, focus group discussions and a diary of class observation specifically related to creativity have proven to be beneficial in this present case study in raising creative awareness among early education student teachers. It is essential to guide future educators in the critical analysis of the "standard classroom", helping them design creative alternatives through collaborative experimentation.

\section{REFERENCES}

Abrami, P. C., Bernard, R. M., Borokhovski, E., Waddington, D. I., Wade, C. A., \& Persson, T. (2014). Strategies for teaching students to think critically: A 
meta-analysis. Review of Educational Research, $X X(\mathrm{X}), \quad 1-40$ doi:10.3102/0034654314551063

Ball, A. F. (2002). Three decades of research on classroom life: Illuminating the classroom communicative lives of America's at-risk students. Review of Research in Education, 26(1), 71-111. doi:10.3102/0091732X026001071

Banaji, S. (2011). Mapping the rhetorics of creativity. In J. Sefton-Green, P. Thomson, K. Jones, \& L. Bresler (Eds.), The Routledge International Handbook of Creative Learning (pp. 36-44). London/New York: Routledge.

Banaji, S., \& Burn, A. (2007). Creativity through a rhetorical lens: Implications for schooling, literacy and media education. Literacy, 41(2), 62-70. doi:10.1111/j.1467-9345.2007.00459.x

Cachia, R., Ferrari, A., Ala-Mutka, K., \& Punie, Y. (2010). Creative Learning and Innovative Teaching (JRC-IPTS Report). Luxembourg: Publications Office of the European Union. doi:10.2791/52913

Chan, S., \& Yuen, M. (2014). Creativity beliefs, creative personality and creativityfostering practices of gifted education teachers and regular class teachers in Hong Kong. Thinking Skills and Creativity, 109-118. doi:10.1016/j.tsc.2014.10.003

Craft, A. (1997). Identity and creativity: Educating teachers for postmodernism? Teacher Development: An International Journal of Teachers' Professional Development, 1(1), 83-96. doi:10.1080/13664539700200001

Craft, A. (2005). Creativity in schools: Tensions and dilemmas. Abingdon: Routledge. doi:10.4324/9780203357965

Craft, A., Gardner, H., \& Claxton, G. (2008). Creativity, wisdom and trusteeship: Exploring the role of education. Thousand Oaks, CA: Corwin Press.

Darras, B. (2011). Creativity, creative class, smart power, social reproduction and symbolic violence. In J. Sefton-Green, P. Thomson, K. Jones, \& L. Bresler (Eds.), The Routledge international handbook of creative learning (pp. 90-98). London/New York: Routledge.

Davies, D., Jindal-Snape, D., Digby, R., Howe, A., Collier, C., \& Hay, P. (2014). The roles and development needs of teachers to promote creativity: A systematic review of literature Teaching and Teacher Education. Teaching and Teacher Education, 34-41. doi:10.1016/j.tate.2014.03.003

Decret 181 de la Generalitat de Catalunya. Diari Oficial de La Generalitat de Catalunya (16/09/2008 pp. 68256-68272).

Drotner, K. (2011). The cult of creativity: Opposition, incorporation, transformation. In J. Sefton-Green, P. Thomson, K. Jones, \& L. Bresler (Eds.), The Routledge international handbook of creative learning (pp. 71-80). London/New York: Routledge.

Hayes, D. (1999). Decisions, decisions, decisions: The process of "getting better at teaching." Teacher Development: An International Journal of Teachers' Professional Development, 3(3), 341-354. doi:10.1080/13664539900200090

Hayes, D. (2011). Ways of knowing and teaching: How teachers create valuable learning opportunities (pedagogical capital) by making knowledge the means and not just the ends in classrooms. In J. Sefton-Green, P. Thomson, K. Jones, \& L. Bresler (Eds.), The Routledge international handbook of creative learning (pp. 200-210). London/New York: Routledge.

Jewitt, C. (2006). Technology, literacy, learning: A multimodality approach. London: Routledge.

Johnston, K., \& Hayes, D. (2008). "This is as good as it gets”: Classroom lessons and learning in challenging circumstances. Australian Journal of Language and Literacy, 31(2), 109-127.

Jones, K. (2011). Capitalism, creativity and learning: Some chapters in a relationship. In J. Sefton-Green, P. Thomson, K. Jones, \& L. Bresler (Eds.), The Routledge international handbook of creative learning (pp. 15-26). London/New York: Routledge.

Kress, G. (2003). Literacy in the New Media Age. London: Routledge. doi:10.4324/9780203164754

Kress, G. (2006). Meaning, learning and representation in a social semiotic approach to multimodal communication. In A. McCabe, M. O’Donnell, \& R. Whittaker (Eds.), Advances in Language and Education (pp. 15-39). London: Continuum.

Kress, G. (2011). English for an era of instability: Aesthetics, ethics, creativity and design. In J. Sefton-Green, P. Thomson, K. Jones, \& L. Bresler (Eds.), The Routledge international handbook of creative learning (pp. 211-216). London/New York: Routledge.

Ley Orgánica 2, Ministerio de la Presidencia (Boletín Oficial Del Estado, 04/052006, pp. 17158-17207).

$\mathrm{Li}, \mathrm{Y}$. (2009). The perspectives and experiences of Hong Kong preschool teacher mentors: Implications for mentoring. Teacher Development, 13(2), 147-158. doi:10.1080/13664530903043970

Mayor, F. (1999). UNESCO appeals for the promotion of arts education and creativity at school to help construct a culture of peace. UNESCOPRESSE No. 99-241. Paris: UNESCO.
National Advisory Committee on Creative and Cultural Education (NACCCE) (1999). All our futures: Creativity, culture \& education (NACCCE Report). London: Author. Retrieved from http://sirkenrobinson.com/pdf/allourfutures.pdf

Resnick, M. (2007). All I really need to know (about creative thinking) I learned (by studying how children learn) in kindergarten. Proceedings of the 6th ACM SIGCHI Conference on Creativity \& Cognition (pp. 1-6). Washington DC: Association for Computing Machinery (ACM). doi:10.1145/1254960.1254961

Sefton-Green, J., \& Bresler, L. (2011). Theories and histories: Creative learning and its contexts. In J. Sefton-Green, P. Thomson, K. Jones, \& L. Bresler (Eds.) The Routledge International Handbook of Creative Learning (pp. 9-14). London/New York: Routledge.

Sefton-Green, J., Thomson, P., Jones, K., \& Bresler, L. (Eds.). (2011). The Routledge international handbook of creative learning. London/New York: Routledge.

Shaheen, R. (2010). Creativity and Education. Creative Education, 1(3), 166-169. doi:10.4236/ce.2010.13026

Singer, E. (2012). Images of the child and the unruly practice. European Early Childhood Education Research Journal, 20(2), 157-161. doi:10.1080/1350293X.2012.681441

Sullivan, G. (2011). The culture of community and a failure of creativity. Teachers College Record, 113(6), 1175-1195.

Thurlings, M., Evers, A. T., \& Vermeulen, M. (2014). Toward a model of explaining teachers' innovative behavior: A literature review. Review of Educational Research, $X X(X), 1-42$. doi:10.3102/0034654314557949

Van Dijk, T. A. (2009). Critical discourse studies: A sociocognitive approach. In R. Wodak \& M. Meyer (Eds.), Methods for Critical Discourse Analysis (2nd ed., pp. 62-86). London, UK: Sage.

Vygotsky, L. S. (2004). Imagination and creativity in childhood. Journal of Russian and East European Psychology, 42(1), 7-97.

Yin, R. K. (1994). Case study research: Design and methods. Thousand Oaks, CA: Sage Publications.

Yuen, A. H. K., Law, N., \& Wong, K. C. (2003). ICT implementation and school leadership: Case studies of ICT integration in teaching and learning. Journal of Educational Administration, 41(2), 158-170. doi:10.1108/09578230310464666

\section{ACKNOWLEDGMENT}

Funded by: Instituto de Ciencias de la Educación de la Facultad de Ciencias de la Educación y Psicología - Universidad Rovira i Virgili, Spain.

Award: B04/14

Project: The training of future teachers from a creative perspective: results and effects of the CLict project 